\title{
Study of the Anatomical Variations in the Nutrient Foramina of Fibula
}

\author{
Hina Majid, Syed Muhammad Yasoob Ali, Rabia Ejaz, Tahira Athar, Mulazim Hussain Bukhari, Salman Shahid
}

\section{ABSTRACT}

Background: The main blood supply to a growing bone is through its nutrient artery. It enters the bone through nutrient foramina (NF). Fibula is commonly used as a bone graft. The anatomical location of NF on fibula is valuable during surgeries. Objective: Topographic assessment of nutrient foramina on human fibulae. Study Design: Cross Sectional Observational Study. Settings: Anatomy Department, Postgraduate Medical Institute, Lahore Pakistan. Duration: 4 months (from 1-12-2018 to 31-3-2019). Methodology: 100 fibulae were obtained from the bone bank of anatomy department, Postgraduate Medical Institute, Lahore. The number of NF and their position on the fibular shaft were observed. Results: Single foramen was observed in $90(90 \%)$ fibulae, $4(4 \%)$ had two foramina, while $6(6 \%)$ had no NF. $86(93 \%)$ foramina were seen on the middle third of the bone. $47(50 \%)$ NF were present on the posterior aspect. $2(2 \%)$ foramina were on the proximal third and $4(4 \%)$ were on the distal third of the fibulae. Conclusion: The posterior aspect and the middle third of the bony shaft bore most of the nutrient foramina.

Keywords: Nutrient artery, Nutrient foramina, Fibula, Orthopedics, Topographic anatomy.

\section{INTRODUCTION}

Nutrient foramen (NF) is an opening that serves as a portal for the vascular supply to the long bones. ${ }^{1}$ Nutrient arteries, after entering the NF supply most of the blood to the bones. $80 \%$ of the blood to the growing bones is supplied by the nutrient arteries. ${ }^{2}$ The vessels placed on the outer periosteum and the inner medullary vessels exhibit a rich intracortical anastomosis. Numerous metaphyseal and epiphysial, and a few diaphyseal arteries provide blood to the long bones. The diaphysis of the long bones is pierced by diaphyseal arteries which enter obliquely.

The location of their entry is usually constant. Upon entering, these arteries give ascending and descending twigs. ${ }^{3} \mathrm{NF}$ becomes oblique in direction with growth. The obliquity from the outside to the marrow cavity indicates the growing end and hence, nutrient foramen is directed opposite to this end. 4,5 The location of $\mathrm{NF}$ in bones may change during development. Even though the NF are directed opposite the growing end of bone, but their location may vary. ${ }^{6}$

Fibula is widely used as a graft as it is a long, straight and a nonweight bearing bone. Reconstruction surgeries after trauma and tumor resection commonly employ fibulae as a vascularized graft. ${ }^{7}$ It is essential to have proper knowledge about the Anatomical relation and variations of fibular artery to the bone shaft before obtaining the free flaps. Major concerns of harvesting these grafts are injuries to the neurovascular bundle and compartment syndromes. ${ }^{8}$ Also the survival of the vascular bone graft depends on the blood supply it receives via the nutrient artery. Therefore, the exact position of NF is helpful to preserve the circulation.

\section{METHODOLOGY}

Study Design: Cross Sectional Observational Study.
Settings: Anatomy Department, Postgraduate Medical Institute, Lahore Pakistan.

Duration: 4 months (from 1-12-2018 to 31-3-2019).

Sample Technique: Non-probability sampling.

Sample Size: 100 dried human fibulae.

Inclusion Criteria: 50 right sided and 50 left sided fibulae

Exclusion Criteria: Broken bones and bones having any pathology.

Methods: 100 dried human fibulae, were collected from the bone bank of anatomy department, Postgraduate Medical Institute, Lahore. The bones studied, were of unknown age and gender. Broken and bones having any gross pathology were excluded from the study. The side of the bone was identified. There were 50 right sided and 50 left sided fibulae. The number of NF and their location on the bones was noted. A hand lens was used to confirm the location of the foramina. Different borders and surfaces of the bone shaft were analyzed for the position of foramina. To confirm the patency, a 24-gauge needle was passed through each foramen.

The number and location of NF was expressed as percentage and frequency. The distance of foramina was calculated using a Vernier caliper and expressed as mean \pm SD. Foraminal index $\mathrm{Fl}$ was calculated using Hughes formula. ${ }^{9}$

\section{RESULTS}

The presence, absence and the number of nutrient foramina were carefully observed and tabulated (Table 1).

The surfaces and borders of fibula were observed for the location of NF was tabulated (Table 2).

The mean fibular length, the mean foraminal index along with $\mathrm{FI}$ ranging was noted (Table 3). Majority of the NF were seen on the middle third. For the bones which had more than one foramen, the larger one was considered for the calculation of FI. 
So total number of foramina taken for the determination of $\mathrm{FI}$ were 92 (Table 4).

Table 1: The number of NF present on the fibula

\begin{tabular}{|c|c|c|}
\hline $\begin{array}{c}\text { No. of nutrient } \\
\text { foramina (NF) }\end{array}$ & $\begin{array}{c}\text { No. of fibulae having these } \\
\text { nutrient foramina (n=100) }\end{array}$ & $\begin{array}{c}\text { Percentage } \\
\%\end{array}$ \\
\hline $\mathbf{0}$ & 6 & $6 \%$ \\
\hline $\mathbf{1}$ & 90 & $90 \%$ \\
\hline $\mathbf{2}$ & 4 & $4 \%$ \\
\hline
\end{tabular}

Table 2: The surface and border on which NF is present on the fibula

\begin{tabular}{|l|c|c|}
\hline $\begin{array}{c}\text { Surface and border } \\
\text { of fibula }\end{array}$ & $\begin{array}{c}\text { Number of fibulas } \\
\text { having NF (n=94) }\end{array}$ & $\begin{array}{c}\text { Percentage } \\
\%\end{array}$ \\
\hline Posterior surface & 47 & $50 \%$ \\
\hline Lateral surface & 4 & $4 \%$ \\
\hline Medial surface & 9 & $10 \%$ \\
\hline Medial crest & 30 & $32 \%$ \\
\hline Anterior border & 0 & $0 \%$ \\
\hline Posterior border & 3 & $3 \%$ \\
\hline Interosseous border & 1 & $1 \%$ \\
\hline
\end{tabular}

Table 3: The length of fibula, distance of NF and foraminal index $\mathrm{FI}$

\begin{tabular}{|c|c|c|c|}
\hline Parameter (n=92) & Mean & Minimum & Maximum \\
\hline length of bone (cm) & $34.56 \pm 4.79$ & 30 & 40 \\
\hline $\begin{array}{c}\text { Foramen distance from } \\
\text { the proximal end (cm) }\end{array}$ & $12 \pm 2.00$ & 8 & 27 \\
\hline FI & 34.7 & 26.6 & 67.5 \\
\hline
\end{tabular}

Table 4: The position of nutrient foramen on the fibular according to $\mathrm{FI}$

\begin{tabular}{|c|c|c|}
\hline $\begin{array}{c}\text { Location of NF } \\
\text { according to FI }\end{array}$ & $\begin{array}{c}\text { Number of fibula } \\
\text { (n=92) }\end{array}$ & Percentage \% \\
\hline Type 1 Proximal 1/3rd & 2 & $2 \%$ \\
\hline Type 2 Middle 1/3rd & 86 & $94 \%$ \\
\hline Type 3 Distal 1/3rd & 4 & $4 \%$ \\
\hline
\end{tabular}

\section{DISCUSSION}

Nutrient foramen is the largest foramen on the long bones through which nutrient artery for that bones passes. The number and the direction of nutrient foramina in fibula vary. These variations hold importance as fibula is used as a vascular graft by orthopedic surgeons.

In the present study, $90 \%(90)$ of the fibulae had a single NF, 4 $(4 \%)$ fibulae had double nutrient foramina, while in the $6(6 \%)$ of the fibulae the nutrient foramen was absent. The result coincides with the researches done by Kizilkanat et al, ${ }^{5}$ and also with the findings of Pereira and his friends. ${ }^{10}$ Sinha and his colleagues observed that among 100 fibulae, $78 \%$ had a single foramen while $22 \%$ bore two foramina. ${ }^{11}$

The study conducted by Vinay and Mangala Gowri showed that 3 fibulae had double nutrient foramina. ${ }^{12}$ Ambekar and Sukre stated that $63.5 \%$ of fibulae had a single foramen, $7.7 \%$ possessed double and $1.9 \%$ of fibulae bore triple nutrient foramina. ${ }^{13}$ Bones which had more than one foramen, the larger among them is the NF, while others are accessory foramina. The main NF contains an artery and vein, while the accessory $\mathrm{NF}$ is a portal for an artery only. ${ }^{14}$

$6 \%$ fibulae had no nutrient foramen. Ongeti, found that NF was absent in $5.5 \%$ fibulae. One reason behind this could be congenital absence of a nutrient artery and the other can be if the nutrient vessel is smaller than $0.5 \mathrm{~mm} .{ }^{15}$

In the present study, the mean length of fibula was $34.56 \mathrm{~cm}$ and the foraminal index was $34.7 \%$ with $\mathrm{FI}$ ranging between 26.6 to $62.5 \%$. The results are close to the findings of Ambekar and Sukre ${ }^{13}$ and also coincides with the findings of the study done by Kalyanasundaram et al. ${ }^{16}$ Vinay et al found that among the South Indians the mean fibular length was $32.58 \mathrm{~cm} .{ }^{12}$ Kizilkanat and friends observed that the fibular length was 34.02 $\mathrm{cm}$ among the Turks ${ }^{5}$, while Mazengenya et al found that the mean length of fibula was $36.76 \mathrm{~cm}$ in the black and $36.07 \mathrm{~cm}$ in the white Africans. ${ }^{17}$

The present study shows that the majority of the NF were located on the posterior surface $(50 \%)$ and on the middle third of the fibula 94\% (Type 2). The results coincide with the research conducted by Gupta and Anusha. ${ }^{18}$

Ojaswini et al, reported $90.8 \%$ NF on the posterior aspect of fibulae with $74 \%$ NF on the middle third, $9 \%$ on lower third and $4 \%$ on upper third of the shaft. ${ }^{19}$

According to the research by Vinay and Mangala Gowri $87.8 \%$ foramina were seen on the back of the bone. ${ }^{12}$ Study done by Arun K et al, on 186 fibulae, reported $29.62 \%$ nutrient foramen on the posterior surface, with $29.62 \%$ of nutrient foramina were located on upper part of the shaft, $38.62 \%$ on the middle and $29.1 \%$ on lower part of the fibular shaft. ${ }^{20}$ Uzma et al, studied 100 fibulae and observed that $62.89 \%$ NF were located on the posterior surface and in $30.9 \%$ were seen along the medial crest. The main factors that affect nutrient foramen position are the growth rates at ends of the shaft and bone remodeling. ${ }^{21}$

\section{CONCLUSION}

The nutrient foramina in fibula were mainly on the middle third of the bone and on its posterior aspect. However other locations cannot be ignored. The knowledge about the topography of nutrient foramen can serve preoperatively during the procurement of vascularized fibular grafts and to avoid injury to the nutrient artery.

\section{LIMITATIONS}

The gender, age and race of the bones were not identified.

\section{SUGGESTIONS / RECOMMENDATIONS}

Further study can be conducted to observe the variations of nutrient foramina among the bone's male and female subjects.

CONFLICT OF INTEREST / DISCLOSURE

There is no conflict of interest involved. 


\section{ACKNOWLEDGEMENT}

The authors acknowledge the academic and research staff of Postgraduate Medical Institute, Lahore for providing technical support and advice.

\section{REFERENCES}

1. Rao VS, Kothapalli J. The diaphyseal nutrient foramina architecture - A study on the human upper and lower limb long bones. J Pharm Biol Sci. 2014;9(1):36-41.

2. Susan Standring. The anatomical basis of clinical practice. 41sted. New York: Elsevier limited; 2016:1405.

3. Collipol E, Vergas R, Parra X, Silva H, Sol M. Diaphysial nutrient foramina in the femur, tibia and fibula bones. Int $\mathrm{J}$ Morphol. 2007;25(2):305-8.

4. Kumar R, Mandloi RS, Singh AK, Kumar D, Mahato P. Analytical and morphometric study of nutrient foramina of femur in rohilkhand region. Int J Med Health Sci. 2013;3(2):52-4.

5. Kizilkanat E, Boyan N, Ozsahin ET, Soames R, Oguz O. Location, number and clinical significance of nutrient foramina in human long bones. Ann Anat. 2007;189(1):87-95.

6. Gupta RK, Kumari GA. A study of diaphyseal nutrient foramina in Human tibia. Nat J Med Res. 2014;4(4):310-3.

7. Ebraheim NA, Elgafy $H, X u$ R. Bone-graft harvesting from iliac and fibular donor sites: Techniques and complications. J Amer Acad Orthop Surg. 2001;9(3):210-8.

8. Choi SW, Kim HJ, Koh KS, Chung IH, Cha IH. Topographical anatomy of the fibula and peroneal artery in Koreans. Int J Oral Maxillofac Surg. 2001;30(4):329-32.

9. Hughes $\mathrm{H}$. The factors determining the direction of the canal for the nutrient artery in the long bones of mammals and birds. Acta Anat (Basel). 1952;15(3):261-80.

10. Pereira GAM, Lopes PTC, Santos AMPV, Silveira FHS. Nutrient Foramina in the Upper and Lower Limb Long Bones:
Morphometric Study in Bones of Southern Brazilian Adults. Int J Morphol. 2011;29(2):514-20.

11. Sinha P, Mishra SR, Kumar P, Gaharwar A. Morphology and topography of nutrient foramina in fibula. Ann Int Med Den Res. 2016;2(6):7-12.

12. Vinay G, Mangala Gowri SR. Anatomical study of the nutrient foramen of lower limb long bones in South Indian population. Indian J Clin Anat Physiol. 2017;4(2):222-4.

13. Ambekar SA, Sukre SB. Diaphyseal nutrient foramen of lower limb long bones: variations and importance. Int $\mathrm{J}$ Anat Res. 2016;4(3):2684-8.

14. Sanjeev K, Kathiresan K, Trinesh G, Nagalaxmi. Study of diaphysial nutrient foramina in human long bones. Anat Kar. 2012;6(2):66-70.

15. Ongeti KW, Obimbo MM, Bundi PK, Ogeng'o J. Anatomical variation of position and location of the fibula nutrient foramen in adult kenyans. East Afr Orthop J. 2007;1(3):16-8.

16. Kalyanasundaram M, Backiaraj $D$, Shalini $R$, Manoranjitham $R$. Morphometric study of nutrient foramen in the long bones of lower limb. Int J Anat Res. 2017;5(2):3943-8.

17. Mazengenya $P$, Faremore MD. Morphometric studies of the nutrient foramen in lower limb long bones of adult black and white South Africans. Eur J Anat. 2015;19(2):155-63.

18. Gupta R, Singh KA, Rajkumar. Morphological study of nutrient foramen in human fibulae of north Indian region. Int J Med Health Sci. 2013;2(2):205-9.

19. Ojaswini M, Hemang J. Diaphyseal nutrient foramina in long bones and miniature long bones. NJIRM. 2011;2(2):23-6.

20. Arun K, BS Reddy. A study on nutrient foramina of fibula, its medicolegal aspect and clinical importance in dentistry. World $\mathrm{J}$ Pharm Pharm Sci. 2014;3(2):2133-44.

21. Uzma R, Nusrat J, Arish NS. Number, direction and location of nutrient foramina of adult fibula and its clinical significance. Int J Sci Res. 2017;6(8):283-5.

\section{AUTHORSHIP AND CONTRIBUTION DECLARATION}

AUTHORS Contribution to The Paper Signatures

\section{Dr. Hina Majid}

Demonstrator, Anatomy Department, Postgraduate

Medical Institute/AMC/LGH, Lahore Pakistan

Prof. Dr. Syed Muhammad Yasoob Ali

Professor \& Head of Anatomy Department, Postgraduate Medical Institute/AMC/LGH, Lahore Pakistan

\section{Dr. Rabia Ejaz}

Demonstrator, Anatomy Department, Postgraduate

Medical Institute/AMC/LGH, Lahore Pakistan

\section{Dr. Tahira Athar}

Demonstrator, Anatomy Department, Services Institute of

Medical Sciences, Lahore

Prof. Dr. Mulazim Hussain Bukhari

Professor \& Head Department of Pathology, University of

Lahore, Lahore

\section{Dr. Salman Shahid}

Department of Public Health, University of Lahore,

Lahore.
Conception \& Design of the Work, Acquisition, Analysis or Interpretation of Data for the Work

Conception \& Design of the Work, Acquisition,

Analysis or Interpretation of Data for the Work

Analysis or Interpretation of Data for the Work

Rabiakjar

Acquisition, Analysis or Interpretation of Data for the Work

Revising Critically for the Important Intellectual Content

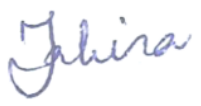

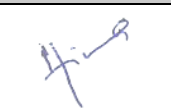

